\title{
Frontiers in Cardiology Research
}

\author{
John Somberg
}

With this issue of the Journal we begin a new series on "Frontiers in Cardiology Research". The series will feature review articles on areas in cardiology where new ideas for research are very much needed. I have asked experts in structural heart disease, arrhythmias, lipidology, heart failure, cell signaling, transplantation, genetics, cell therapy and regenerative medicine to submit papers on research frontiers in the areas of their expertise. Readers of the Journal are also welcome to submit papers for the "Frontiers in Cardiology Research Series".

While research in many areas of cardiology are proceeding at tremendous speed, it is always good to highlight certain areas, rethink others and reinvigorate areas where researchers have become repetitive with little clinical application. I encourage all our readers and contributors not to just remain observers, complacent with the encyclopedic advance of knowledge in cardiology, but to focus on the next steps needed in basic and translational research to further patient care.

In the first article of the series I highlight an "old drug" I have been working on that has recently been re-introduced into clinical practice. There are significant unanswered questions surrounding the agent, bretylium and cardiac resuscitation. Perhaps the first review article will initiate research to address some of these issues.

\section{Acknowledgments}

None to declare.

\section{Financial Disclosure}

None to declare.

\section{Conflict of Interest}

None to declare.

\section{Data Availability}

The author declares that data supporting the findings of this study are available within the article. 